\title{
Pericarditis with Atrial Septal Defect with Bilateral Haemorrhagic Ovarian Cyst: A Case Report
}

\author{
MOHAMMAD SERAJUS SALEKIN ${ }^{1}$, OMAR SADEQUE KHAN ${ }^{1}$, SHARMIN JAHAN URME ${ }^{2}$, \\ ASIT BARAN ADHIKARY ${ }^{1}$, MD. AFTABUDDIN ${ }^{1}$ \\ ${ }^{1}$ Department of Cardiac Surgery, Bangabandhu Sheikh Mujib Medical University, Bangladesh, ²Department of Gynae and \\ Obstetrics, Shaheed Suhrawardy Medical College Hospital.
}

Address of Correspondence: Professor Dr. Md. Aftabuddin, Chairman, Department of Cardiac Surgery, Bangabandhu Sheikh Mujib Medical University, Bangladesh, E-mail: aftab12uddin@yahoo.com

\begin{abstract}
:
We are reporting a case of bilateral haemorrhagic ovarian cyst with pericarditis with atrial septal defect (ASD) in a 32 years female. Diagnosis of ASD was incidental when she was under evaluation for bilateral haemorrhagic ovarian cyst. Diagnosis was confirmed by echocardiography. ASD was closed by Polytetrafluoroethylene (PTFE) patch. Pericardium was found full of multiple small whitish granular nodules. So pericardium was discarded as a patch. Pericardium was sent for histopathology and histopathology reveals chronic pericarditis. Postoperative course was uneventful with marked improvement of symptoms.
\end{abstract}

\section{Introduction:}

ASD is a common congenital heart disease. Secondum type of ASD occurs in 1 in 1500 live birth, accounting for $10 \%$ to $15 \%$ of congenital heart disease in children and 20 to $40 \%$ of defect discovered in adult. ${ }^{1}$ Women are affected twice as often as men. ${ }^{1}$ Complication of the disease condition can be found like migraine, stroke and diver's decompression illness. 2,3,4 Also there is association with other anomaly such as persistent left superior vena cava, mild or moderate pulmonary stenosis, azygos extension of inferior vena cava, small persistent ductus arteriosus, coarctation of aorta, cleft mitral valve. ${ }^{5}$ Here we are presenting a case who was under treatment for ovarian cyst and ASD with pericarditis was an incidental finding. (Fig. 1).

\section{Case report}

A 32 year old woman presented with breathlessness since childhood. Dysmenorrhoea and menorrhagia for 7 years. Patient also had lower abdominal pain for 1 year. The general examination revealed no anaemia, cyanosis, jaundice, clubbing, edema or dehydration. Cardiovascular examination showed normal $1^{\text {st }}$ heart sound and fixed splitting of $2^{\text {nd }}$ heart sound. There was a soft systolic flow murmur in pulmonary area. Patients CBC showed Hb\% $11.8 \mathrm{~g} / \mathrm{dl}$, ESR $25 \mathrm{~mm}$ in $1^{\text {st }}$ hour, total W.B.C. count 15000/cmm, Neutrophil 70\%, Lymphocyte $25 \%$, Monocyte $4 \%$, Mantoux test and sputum for AFB were negative. Chest $\mathrm{X}$ ray showed mild cardiomegaly. Echocardiogram showed large secondum type of ASD (25 $\mathrm{mm}$ ), and mild pulmonary hypertension (PASP $46 \mathrm{~mm}$ of $\mathrm{Hg}$ ) with dilated right atrium, right ventricle and pulmonary trunk. Cardiac catheterization was done. There was step up of O2 saturation at midatrial level. Qp/Qs was 2:1. Ultrasonography of the lower abdomen showed enlarged both ovaries containing multiple cysts - suggesting haemorrhagic cyst. Serum CA -
19.9 was $17.3 \mathrm{U} / \mathrm{ml}$ and CA -125 was $38.4 \mathrm{u} / \mathrm{ml}$ which was 3 units higher than normal reference range. The patient underwent surgical closure of ASD. The patient was placed in supine position. Anesthesia was given. Standard median sternotomy done. After pericardiotomy pericardium showed multiple whitish granular nodules in the inner surface of pericardium and also some thread like structure was found along with it. Cardiopulmonary bypass was established by bicaval cannulation. After attaining mild $\left(32^{\circ} \mathrm{C}\right)$ hypothermia cross clamp was given on the aorta and antegrade cardioplegia was given. After right atriotomy ASD was found with a size about $30 X 20 \mathrm{~mm}$. ASD was closed using Polytetrafluoroethylene (PTFE) patch. Right atrium was closed in layers. Weaning from cardiopulmonary bypass was done without any difficulty. Pericardial biopsy was taken and sent for histopathology. Postoperative recovery was uneventful. Histopathology showed chronic pericarditis. (Fig.1)

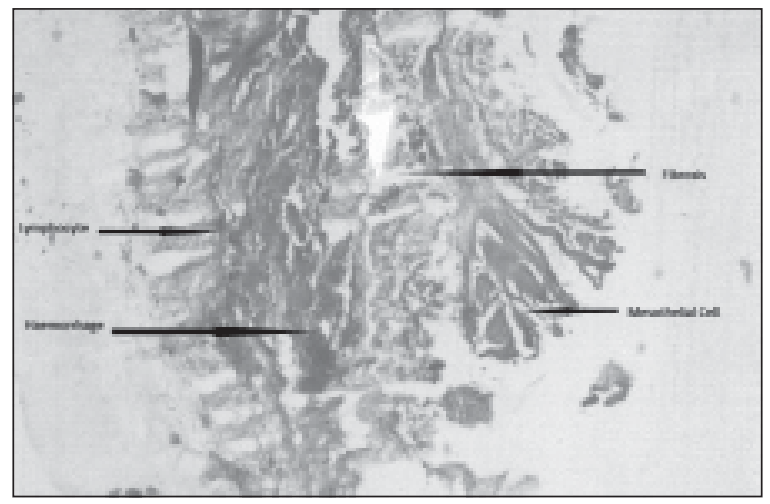

Fig.-1: Photomicrograph (10X magnification) of Pericardium stained with Haematoxylin and eosin shows Mesothelial cell, Fibrosis, Haemorrhage and Lymphocyte suggestive of Pericarditis. 


\section{Discussion:}

There are a few case reports on ASD with pericarditis. Yoshihisa and colleagues found one case where transthoracic echocardiography demonstrated ASD but the finding of thickened pericardium was poor. Diagnosis was confirmed by catheterization. Pericardiotomy and direct closure of ASD was performed. ${ }^{6}$ Harada and colleagues presented two cases of ASD with pericarditis where patients were 1 and 13 years old. ${ }^{7}$ One patient died soon after surgery due to low cardiac output. The other patient was associated with protein-loosing enteropathy and it improved dramatically after operation. ${ }^{7}$ Kanda and colleagues reported a case where signs of ASD were masked by those of pericarditis. Diagnosis was made by MRI and Doppler echo and confirmed by catheterization. ${ }^{8}$ Tanaka and colleagues reported a case where ASD was missed at first operation because diagnosis of ASD was difficult. ${ }^{9}$ We have experienced a surgical repair of ASD in 32 year female who also had bilateral haemorrhagic ovarian cyst. Her ASD diagnosis was incidental. She was under gynaecological consultation regarding ovarian cyst. Pre-operative echocardiography revealed ASD. Though she was having mild breathlessness on exertion she never took medical advice. During operative procedure, pericardium was found full of multiple small whitish granular nodules which give rise to a suspicion of tubercular pericarditis, though histopathology showed chronic pericarditis. Preoperative investigation could not diagnose pericarditis. Pericarditis is difficult to diagnose by investigations like echocardiography and cardiac catheterization.

\section{Conclusion:}

Atrial septal defect is a congenital condition and is not related with pericarditis or bilateral haemorrhagic ovarian cyst. We present the case as it is a rare finding in our long experience.

\section{References:}

1. Campbell M. Natural history of atrial septal defect. Br Heart J 1970; 32:820-6.

2. Schwedt TJ, Demaerschalk BM, Dodick DW. Patent foramen ovale and migraine: a quantitative systemic review. Cephalalgia 2008; 28:531-40.

3. Overell JR, Bone I, Lees KR. Interatrial septal abnormalities and stroke. A meta-analysis of case control studies. Neurology 2000; 55:1172-9.

4. Boussuges A, Blatteau JE, Pointer JM. Bubbbles in the left cardiac cavities after diving. Heart 2008; 2:445-6.

5. TK, Eugene HB, Donald BD, Frank LH, Robert BK .Atrial Septal Defect and Partial Anomalous Pulmonary Venous Connection. Kirklin/Barratt-Boyes Cardiac Surgery. $3^{\text {rd }}$ ed. Churchill Livingston; 2003.722-3.

6. Yoshihisa MD, Yukihiro, Takashi. Constrictive pericarditis with atrial septal defect. Ann Thoracic Cardiovasc Sur 2006; 12: 373-5.

7. Harada K, Seki I, Okuni M. Constrictive pericarditis with atrial septal defect in children. Japan heart 1978; 19:531-43.

8. Kanda T,Naganuma F. Masked atrial septal defect in constrictive pericarditis. J Med 1993; 24:325-32.

9. Tanaka K, Murota Y. A case of recurrent constrictive pericarditis complicated with atrial septal defect. Nihon Kyobu Geka Gekkai Zasshi. 1995; 43: 1195-7. 